\title{
Assessing Biodegradation Susceptibilities of Selected Petroleum Hydrocarbons at Contaminated Soils
}

\author{
Markus Heryanto Langsa ${ }^{1}$ \\ Received 4 May 2009 / accepted 1 November 2009
}

\begin{abstract}
Assessing Biodegradation Susceptibilities of Selected Petroleum Hydrocarbons at Contaminated Soils (MH Langsa): The susceptibility to biodegradation of selected saturated hydrocarbons (SHCs), polycyclic aromatic hydrocarbons (PAHs) and asphaltenes in a Barrow crude oil and extracts isolated from soils contaminated with the Barrow crude oil at day 0 and 39 was determined. Soil samples were contaminated with a Barrow crude oil across the surface $(5 \% \mathrm{w} / \mathrm{w})$ as part of a mesocosm experiment in order to mimic similar conditions in the environment. The extent of biodegradation of the Barrow oil extracted from the contaminated soils at day 0 and day 39 was assessed by GC-MS analyses of SHCs and PAHs fractions. Changes in the relative abundances of $n$-alkanes (loss of low-molecularweight hydrocarbons) and pristane relative to phytane $(\mathrm{Pr} / \mathrm{Ph})$ and their diastereoisomers were determined. Changes in the diastereoisomer ratios of $\mathrm{Pr}$ and $\mathrm{Ph}$ relate to the decrease in abundance of the phytol-derived $6(R), 10(S)$ isoprenoids with increasing biodegradation. The percentage change in abundances of each of selected alkylnaphathalenes with time (day 0 to 39) was determined, enabling an order of susceptibility of their isomers to biodegradation. It was established that the 2-methylnaphthalene isomers (2-MN) is more susceptible to microbial attack than 1-MN isomer indicated by decreasing in percent abundance from day 0 to 39 for the $2-\mathrm{MN}$ isomer. The GC-MS analyses of the original Barrow oil indicated the oil had not undergone biodegradation. When this oil was used in the soil mesocosm experiments the oil was shown to biodegrade to about a level $2-3$ based on the biodegradation susceptibility of the various SHCs and PAHs described above.
\end{abstract}

Keywords: Biodegradation, contaminated soils, polycyclic aromatic hydrocarbons (PAHs) saturated hydrocarbons (SHCs)

\section{INTRODUCTION}

The impact that an oil spill has on the environment depends on many factors, including the chemical and physical nature of the oil or refined product, the local environmental conditions (i.e. wind currents, temperature, salinity and biota). Some oil spills are quickly bioremediaded whereas other spills can have long-term effects spanning several years (Fisher et al. 1998; Peters and Moldowan 1993).

Bioremediation is a process that encourages microbial populations to degrade hydrocarbon contaminants (Barron 2004). Microbial degradation is one of the most effective methods to remediate oil from soil or sediment after a spill. The toxicity of the contaminants is reduced because bioremediation transforms xenobiotics introduced into the environment to less toxic or innocuous forms, and/or mineralises them to $\mathrm{CO}_{2}, \mathrm{H}_{2} \mathrm{O}, \mathrm{O}_{2}$ and other inorganic products. Thus migration of contaminants is usually prevented and ecological recovery is usually promoted.

Numerous studies also have been made to measure the effects of biodegradation on aromatic hydrocarbon distributions in soils (e.g., Bispo et al. 1999; Budzinski et al. 1998; Chang et al. 2002; Henner et al. 1999; Loehr 1991; Pospisil et al. 1996; Sauer et al. 1998; Skiba et al. 1992). Similar results to those reported above for reservoired oils have been observed for soils. For example, the rate of aromatic family biodegradation decreases with increasing aromatic rings (or molecular weight or boiling point), similar to what would generally be predicted through evaporation. Naphthalenes degrades faster than the

\footnotetext{
${ }^{1}$ Department of Chemistry, Faculty of Mathematics and Sciences, The University of Papua, Jl. Gunung Salju Amban Manokwari Papua Barat, 98314. Telephone: (0986) 215057/ (0986) 211753.

Email: herilangsa@yahoo.com
}

J Trop Soils, Vol. 15, No. 1, 2010: 39-47

ISSN 0852-257X 
phenanthrenes and dibenzothiophenes and chrysene is one of the most resistant to biodegradation (Sauer et al. 1998). Within individual compound classes, some isomers are more susceptible to biodegradation than others, and this is controlled by the position of the alkyl substituent's on the aromatic ring (Huang et al. 2004). In a soil studied by Pospisil et al. (1996), it was found that the concentration of the aromatic hydrocarbons with three and four-rings decreased to about $0.5 \%$ of the original oil.

Barrow Island is a region where the climate is arid and the island experiences very high temperatures exceeding $30^{\circ} \mathrm{C}$, which means bacterial biodegradation is a slow process and the oil pollutants in that area will take a significantly longer period of time to degrade (Davie 2004). It has been recognised that because of these climatic conditions, action needs to be taken in order to optimise the bacterial activity. In a study by Watkins (1996) fertilizers were added to the soil to act as a carbon source for the bacteria and to promote bioremediation in that area.

The main objective of this study is to observe the rate of biodegradation of the Barrow crude oil in soil after production flowline leaks, including polycyclic aromatic hydrocarbons (PAHs) and saturated hydrocarbons (SHCs). This will be performed by a mesocosm experiment. GC-MS analyses of the saturates and aromatics fractions from the crude oils before and after contamination will be carried out and changes in abundances of compounds will be rigorously assessed. By testing the effects of crude oil on soil composition, this research will represent how production flowline leaks are affecting the soils on Barrow Island. These results may then be used as a basis for further detailed research and also provide clues on better management of contaminated sites upon the island.

\section{MATERIALS AND METHODS}

\section{Soil Samples}

Soil samples provided by the Centre of Land Rehabilitation Laboratory UWA were collected from the top $20 \mathrm{~cm}$ of the soil profile on Barrow Island. Several physical properties of the soil were measured by UWA's laboratory. These properties include water holding capacity and soil moisture content. A vessel of contaminated soil was prepared in a $500 \mathrm{~mL}$ sealed glass jar containing $100 \mathrm{~g}$ of soil. The soil holding water capacity was adjusted to around $50 \%$. The appropriate amount of oil $(5 \% \mathrm{w} / \mathrm{w})$ was applied to 40 obtain an even distribution of oil across the surface of the soil to imitate the similar conditions in the field. Two replicates were used. The vessels were sealed after adding the oil and left to incubate for 39 days at $25^{\circ} \mathrm{C}$. The $\%$ of extractable hydrocarbons (saturated, aromatic and polar hydrocarbons, NSOs) was measured on day 0 and day 39 .

\section{Extraction Soil Contaminated Oil}

Soil samples were dried at room temperature. The ground soils were extracted by using an accelerated solvent extractor using 9:1 mixture of dichloromethane and methanol. Extracts were dried under a nitrogen purge and weighed.

\section{Crude Oil}

Crude oil was provided by the Centre of Land Rehabilitation Laboratory UWA. The oil was collected from the production flowlines on Barrow Island. The whole crude has a specific gravity of 0.8363 , a sulphur content of $500 \mathrm{mg} \mathrm{kg}^{-1}$ and a nitrogen content of 320 $\mathrm{mg} \mathrm{kg}^{-1}$. The crude oil is composed of $95 \%$ hydrogen and carbon, with smaller quantities of additional elements including sulphur, oxygen, nitrogen and metals.

\section{Separation of Saturated, Aromatic and Polar Hydrocarbons (NSO) by Silica-Gel Chromatography}

In a typical small-scale separation, the crude oil or maltenes fraction (20 mg $~ 2$ drops) was applied to the top of a small column $(6 \mathrm{~cm} \times 0.4 \mathrm{~cm})$ of activated $\left(120^{\circ} \mathrm{C}\right.$, overnight $)$ silica gel pre-eluted with pentane. The aliphatic hydrocarbon (saturate) fraction was eluted with pentane $(2 \mathrm{~mL})$; the aromatic fraction with a solution of dichlromethane (DCM) in pentane ( $2 \mathrm{~mL}, 30 \%)$; and the polar fraction with a solution of equal parts of DCM and methanol $(2 \mathrm{~mL})$. The resulting saturate (10 drops) and aromatic fractions (20 drops) were diluted with hexane for analysis by GC-MS.

\section{RESULTS AND DISCUSSION}

\section{Identification of Naphthalene and Alkylnaphthalenes}

Naphthalene and alkylnaphthalenes are some of the major components of the aromatic fraction. These compounds were identified using their molecular ion mass chromatograms as shown in Figure 1. 


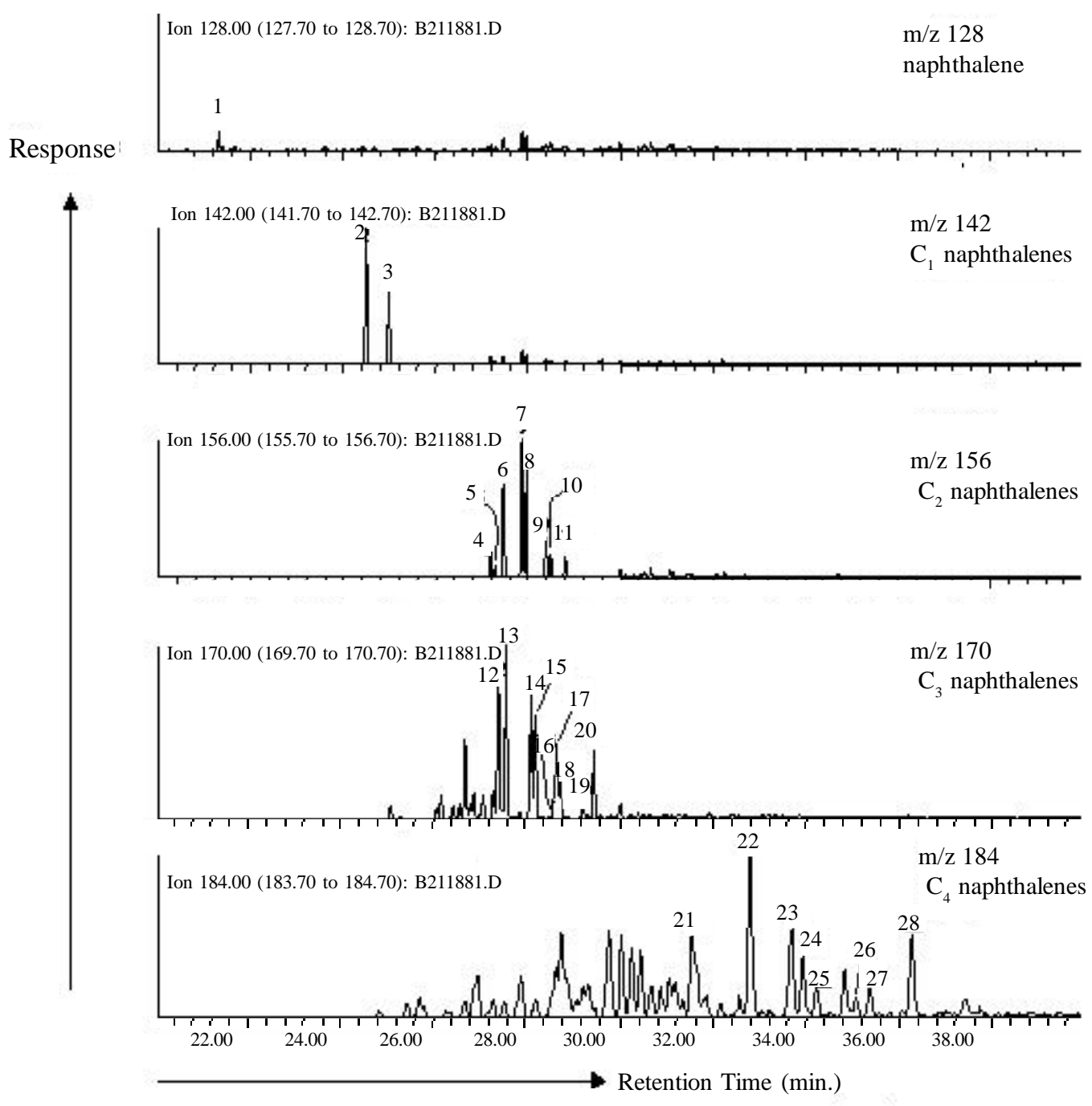

Figure 1. Partial mass chromatograms showing the distribution of naphthalene and its alkylated derivatives in the original Barrow crude oil.

Naphthalene $(\mathrm{m} / \mathrm{z}, 128)$ was assigned based on its mass spectrum and by comparison of retention time with that of a reference sample The alkyl isomers, i.e. methyl- $(\mathrm{m} / \mathrm{z}$ 142), dimethyl- $(\mathrm{m} / \mathrm{z} 156)$, trimethyl- $(\mathrm{m} /$ $z$ 170) and tetramethylnaphthalenes $(\mathrm{m} / \mathrm{z}, 184)$ were identified by comparing retention times and mass spectra with those reported in the chemical literature (Brown and Maher 1992; Jiang 1998; Volkman et al. 1984).

\section{The Effect of Biodegradation on Individual Alkylnaphthalene Isomers of Extracted Oil from Soil}

Selected mass chromatograms reveal the presence of naphthalene, the MNs, the DMNs, TMNsand TeMNs in the aromatic hydrocarbon fraction from the original oil, extracted oil at day 0 and 39 shown in Figure 2. Inspection of these chromatograms depicts that only naphthalene is almost completely removed from the oil extracted from biodegraded oil contaminated for 39 days whereas the MNs, the DMNs, the TMNs and TeMNs isomers are slightly altered.

The peak areas for the alkylnaphthalene isomers were determined and plotted as $\%$ change in relative abundance calculated from the contribution of each alkylnaphthalene isomer to the total sum of the isomers. The results for these treatments are presented graphically in Figure 3. It is evident that $2-\mathrm{MN}$ is decreasing in $\%$ abundance from day 0 to 39 whereas $1-\mathrm{MN}$ is increasing in \% abundance. Thus the $2-\mathrm{MN}$ 
Table 1. Aromatic compounds identified in samples.

\begin{tabular}{|c|c|c|c|c|}
\hline $\begin{array}{l}\text { Peak } \\
\text { No. }\end{array}$ & Compound & $\begin{array}{l}\text { Name } \\
\text { abbreviation }\end{array}$ & $\begin{array}{l}\text { Molecular } \\
\text { ion }\end{array}$ & $\begin{array}{l}\text { Mass number } \\
\text { for quanti. }\end{array}$ \\
\hline 1 & Naphthalene & $\mathrm{N}$ & 128 & 128 \\
\hline 2 & 2-Methylnaphthalene & 2-MN & 142 & 142 \\
\hline 3 & 1-Methylnaphthalene & $1-\mathrm{MN}$ & 142 & 142 \\
\hline 4 & 2-Ethylnaphthalene & 2-EN & 156 & 156 \\
\hline 5 & 1-Ethylnaphthalene & 1-EN & 156 & 156 \\
\hline 6 & 2,6-Dimethylnaphthalene & 2,6-DMN & 156 & 156 \\
\hline 7 & 1,3-Dimethylnaphthalene & 1,3-DMN & 156 & 156 \\
\hline 8 & 1,6-Dimethylnaphthalene & 1,6-DMN & 156 & 156 \\
\hline 9 & 1,4-Dimethylnaphthalene & 1,4-DMN & 156 & 156 \\
\hline 10 & 1,5-Dimethylnaphthalene & 1,5-DMN & 156 & 156 \\
\hline 11 & 1,2-Dimethylnaphthalene & 1,2-DMN & 156 & 156 \\
\hline 12 & 1,3,7-Trimethylnaphthalene & $1,3,7-\mathrm{TMN}$ & 170 & 170 \\
\hline 13 & 1,3,6-Trimethylnaphthalene & $1,3,6-\mathrm{TMN}$ & 170 & 170 \\
\hline 14 & 1,4,6-Trimethylnaphthalene & $1,4,6-\mathrm{TMN}$ & 170 & 170 \\
\hline 15 & 2,3,6-Trimethylnaphthalene & 2,3,6-TMN & 170 & 170 \\
\hline 16 & 1,2,7-Trimethylnaphthalene & $1,2,7-\mathrm{TMN}$ & 170 & 170 \\
\hline 17 & 1,6,7-Trimethylnaphthalene & $1,6,7-\mathrm{TMN}$ & 170 & 170 \\
\hline 18 & 1,2,6-Trimethylnaphthalene & $1,2,6-\mathrm{TMN}$ & 170 & 170 \\
\hline 19 & 1,2,4-Trimethylnaphthalene & $1,2,4-\mathrm{TMN}$ & 170 & 170 \\
\hline 20 & 1,2,5-Trimethylnaphthalene & $1,2,5-\mathrm{TMN}$ & 170 & 170 \\
\hline 21 & 1,3,5,7-Tetramethylnaphthalene & $1,3,5,7-\mathrm{TeMN}$ & 184 & 184 \\
\hline 22 & 1,3,6,7-Tetramethylnaphthalene & $1,3,6,7-\mathrm{TeMN}$ & 184 & 184 \\
\hline 23 & 1,2,4,7-Tetramethylnaphthalene & $1,2,4,7-\mathrm{TeMN}$ & 184 & 184 \\
\hline 24 & 1,2,5,7-Tetramethylnaphthalene & $1,2,5,7-\mathrm{TeMN}$ & 184 & 184 \\
\hline 25 & 2,3,6,7-Tetramethylnaphthalene & 2,3,6,7-TeMN & 184 & 184 \\
\hline 26 & 1,2,3,7-Tetramethylnaphthalene & $1,2,3,7-\mathrm{TeMN}$ & 184 & 184 \\
\hline 27 & 1,2,3,6-Tetramethylnaphthalene & 1,2,3,6-TeMN & 184 & 184 \\
\hline 28 & 1,2,5,6-Tetramethylnaphthalene & $1,2,5,6-\mathrm{TeMN}$ & 184 & 184 \\
\hline
\end{tabular}

is easily biodegraded and therefore most susceptible to biodegradation.

\section{The Effect of Biodegradation on Individual Alkylnaphthalene Isomers of Extracted Oil from Soil}

Selected mass chromatograms reveal the presence of naphthalene, the MNs, the DMNs, TMNs and TeMNs in the aromatic hydrocarbon fraction from the original oil, extracted oil at day 0 and 39 shown in Figure 2. Inspection of these chromatograms depicts that only naphthalene is almost completely removed from the oil extracted from biodegraded oil contaminated for 39 days whereas the MNs, the DMNs, the TMNs and TeMNs isomers are slightly altered.

The peak areas for the alkylnaphthalene isomers were determined and plotted as $\%$ change in relative abundance calculated from the contribution of each alkylnaphthalene isomer to the total sum of the 42 isomers. The results for these treatments are presented graphically in Figure 3. It is evident that 2$\mathrm{MN}$ is decreasing in \% abundance from day 0 to 39 whereas $1-\mathrm{MN}$ is increasing in $\%$ abundance. Thus the 2-MN is easily biodegraded and therefore the most susceptible to biodegradation.

As can be seen from Figure 3(b) that 2,6-DMN is also decreasing in $\%$ abundance to a greater extent than the other DMNs suggested that this isomer is far more susceptible to biodegradation than the other DMNs. 1,3-DMN, 1,5-DMN and 1,6-DMN appear to be fairly resistant to biodegradation indicated by increasing in \% abundances, while 1,2-DMN and 1,4DMN are intermediate. Susceptibility in ENs is also evident with 2-EN appears to have been easily removed relative to 1 -EN shown by increasing in \% abundances of this isomer after being contaminated with the soil for 39 days.

The TMNs were examined and results of \% abundances are presented in Figure 3(d). It is immediately apparent that 2,3,6-TMN shows a 

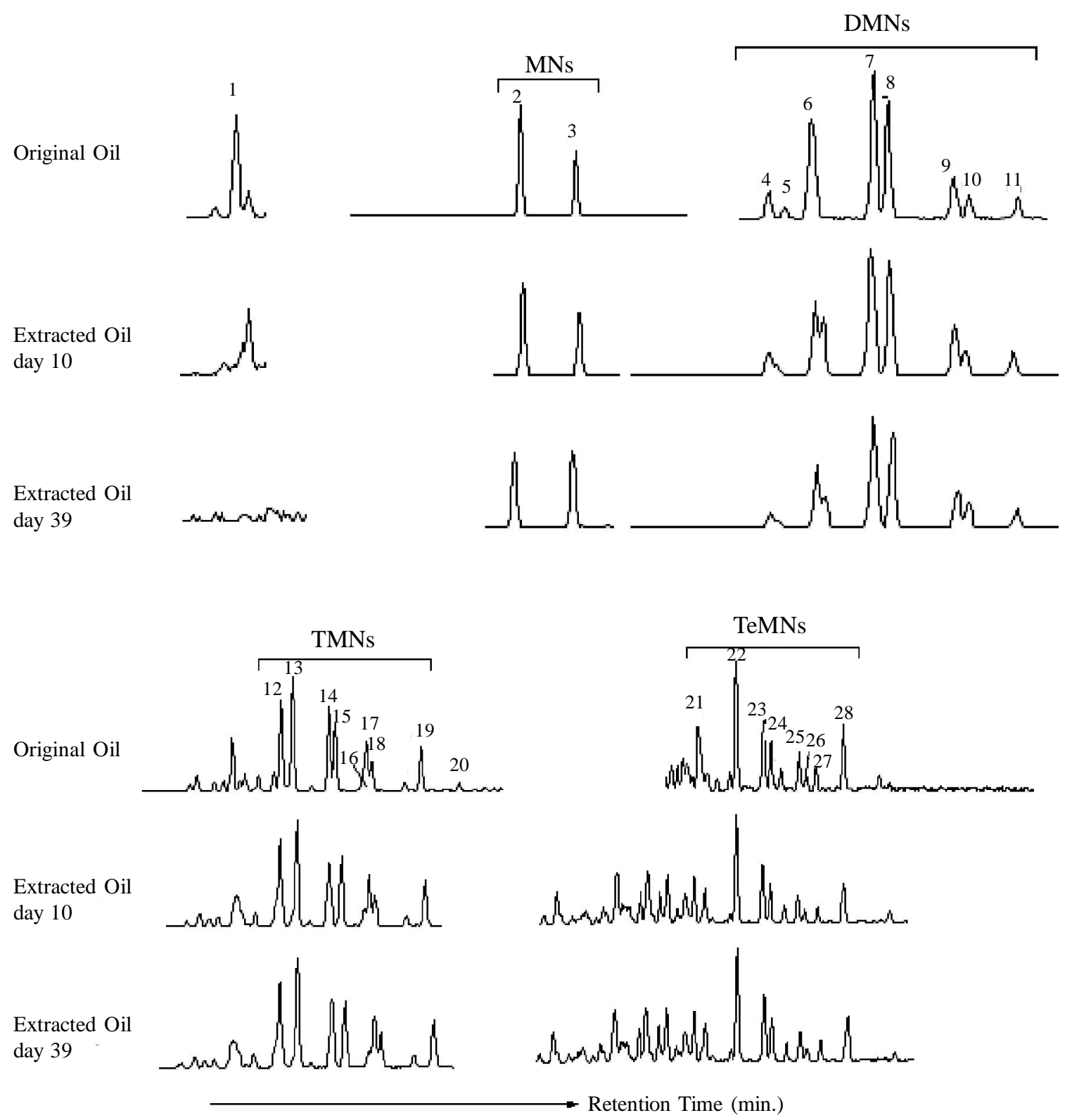

Figure 2. Mass chromatograms showing naphthalene $(\mathrm{m} / \mathrm{z}$ 128), methylnaphthalenes (MNs, $\mathrm{m} / \mathrm{z} 142$ ), dimethylnaphthalenes (DMNs, $\mathrm{m} / z$ 156), trimethylnaphthalenes (TMNs, $\mathrm{m} / \mathrm{z} 170$ ), and tetramethylnaphthalenes (TeMNs, $\mathrm{m} / \mathrm{z}$ 184) present in oil samples (refer to Table 2.2 for peak identification).

decrease in \% abundance where as 1,4,6-TMN displays an increase in $\%$ abundance. This indicates that 2,3,4-TMN is the most susceptible isomer to biodegradation in the TMN isomers whereas $1,4,6-$ TMN is the least resistant to biodegradation. The \% for 1,2,7-TMN, 1,2,5-TMN, 1,2,6-TMN and 1,2,4TMN are intermediate.

The results from the analysis of the TeMN are presented in Figure 3(e). It is evident that most of the isomers remain relatively unaltered indicated by almost parallel the bar graph of the isomers from the oil samples. The only slight decrease in \% abundance is for 1,3,5,7-TeMN perhaps indicating this isomer is easily removed by biodegradation. 1,2,3,6-TeMN, 1,2,5,6-TeMN, 1,2,5,7-TeMN, and 2,3,6,7-TeMN are relatively constant while $1,2,3,7-\mathrm{TeMN}$ is slightly increasing in \% abundance showing that this compound is most resistant to biodegradation.

From the findings presented by $\%$ change in abundances of each alkylnaphthalene relative to the 
(a) Methylnaphthalenes

- $1-\mathrm{MN} \mathbf{D}_{2}-\mathrm{MN}$

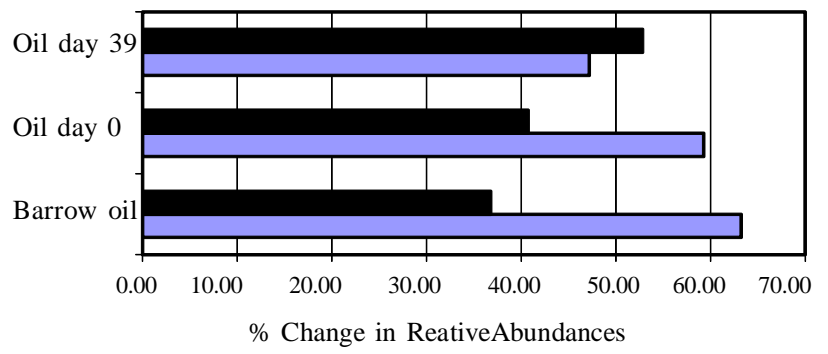

(b) Dimethylnaphthalenes

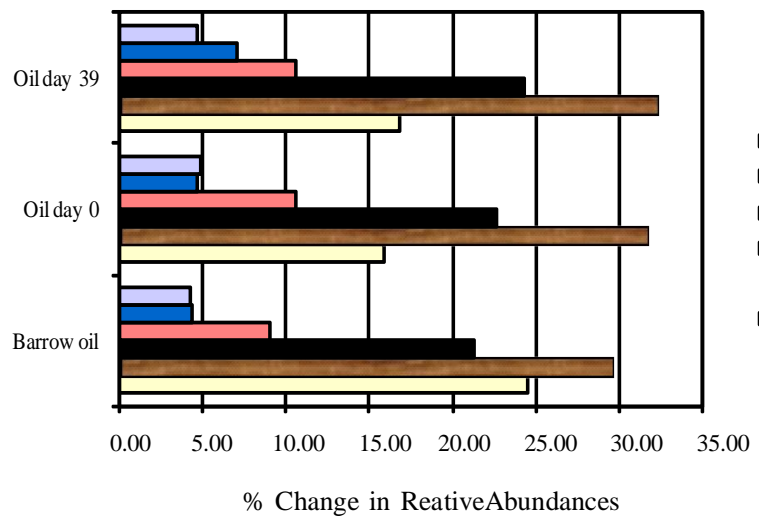

(c) Ethylnaphthalenes

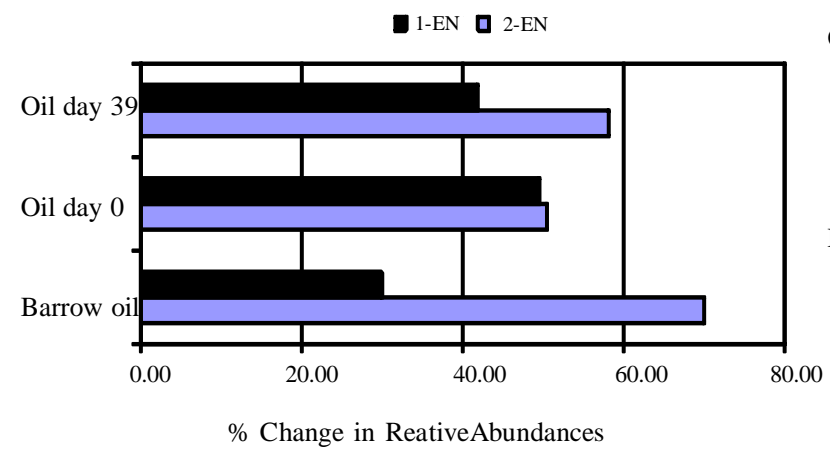

(d) Trimethylnaphthalenes

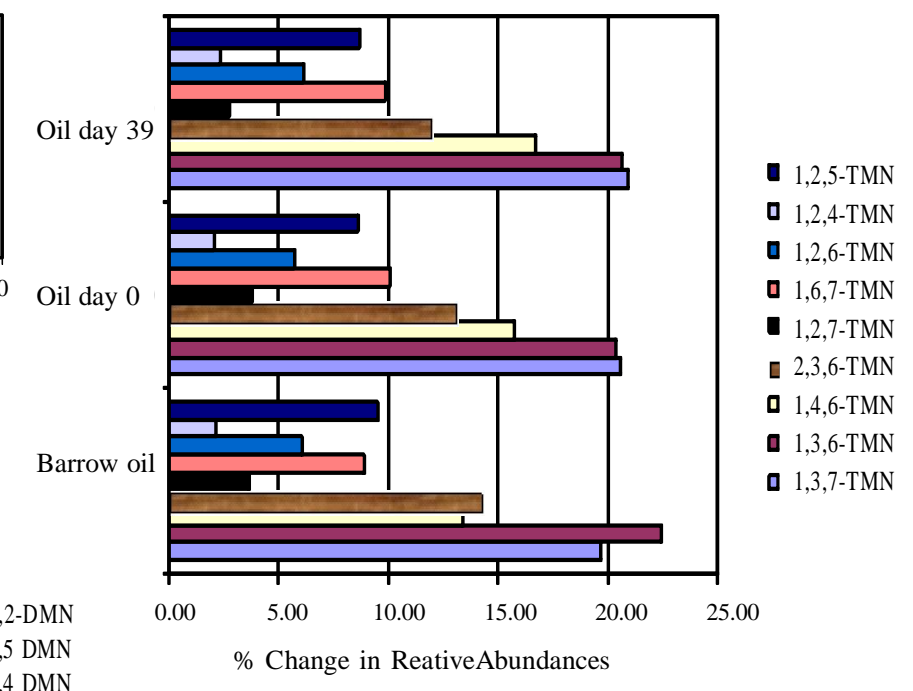

(e) Tetramethylnaphthalenes
1,3 DMN

Oil day 39

Oil day 0

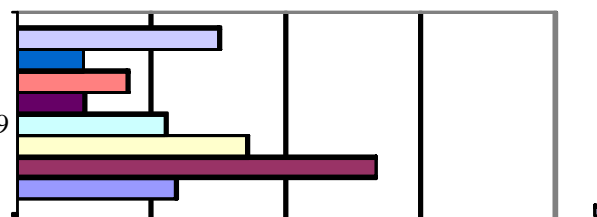

व 1,2,5,6-TTMN

घ1,2,3,6-TTMN

1,2,3,7-TTMN

- 2,3,6,7-TTMN

- 1,2,5,7-TTMN

1,2,4,7-TMN

- 1,3,6,7-TTMN

Barrow oil

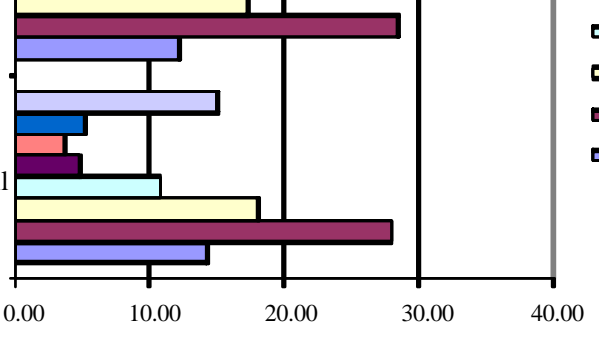

$\%$ Change in ReativeAbundances

Figure 3. Bar graph showing \% changes in abundance of MNs (a), DMNs (b), ENs (c), TMNs (d), and TeMNs (e) from original oil and oil samples taken from soil in mesocosm at day 0 and day 39.

sum of the isomers shows the Barrow oil has been biodegraded over time. The depletion of naphthalene in samples at day 0 and 39 is probably due to evaporation of this compound. The decrease in \% abundance of 2-MN relative to the 1-MN, the changes in the distributions of DMNs and TMNs with time indicate the oil has been biodegraded. The \% abundances of TeMNs remain relatively unaltered.

Based on these results and previously reported data the oil at day 0 and 39 are equivalent to a biodegradation level 2 to 3 . The following is a summary of susceptibility to biodegradation of the various alkylnaphthalene isomers.

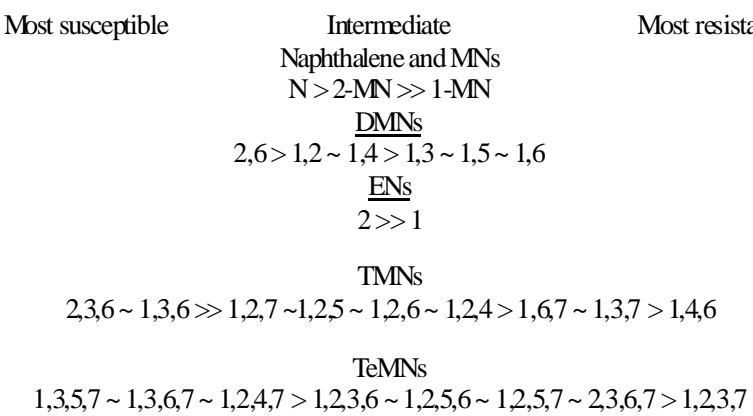




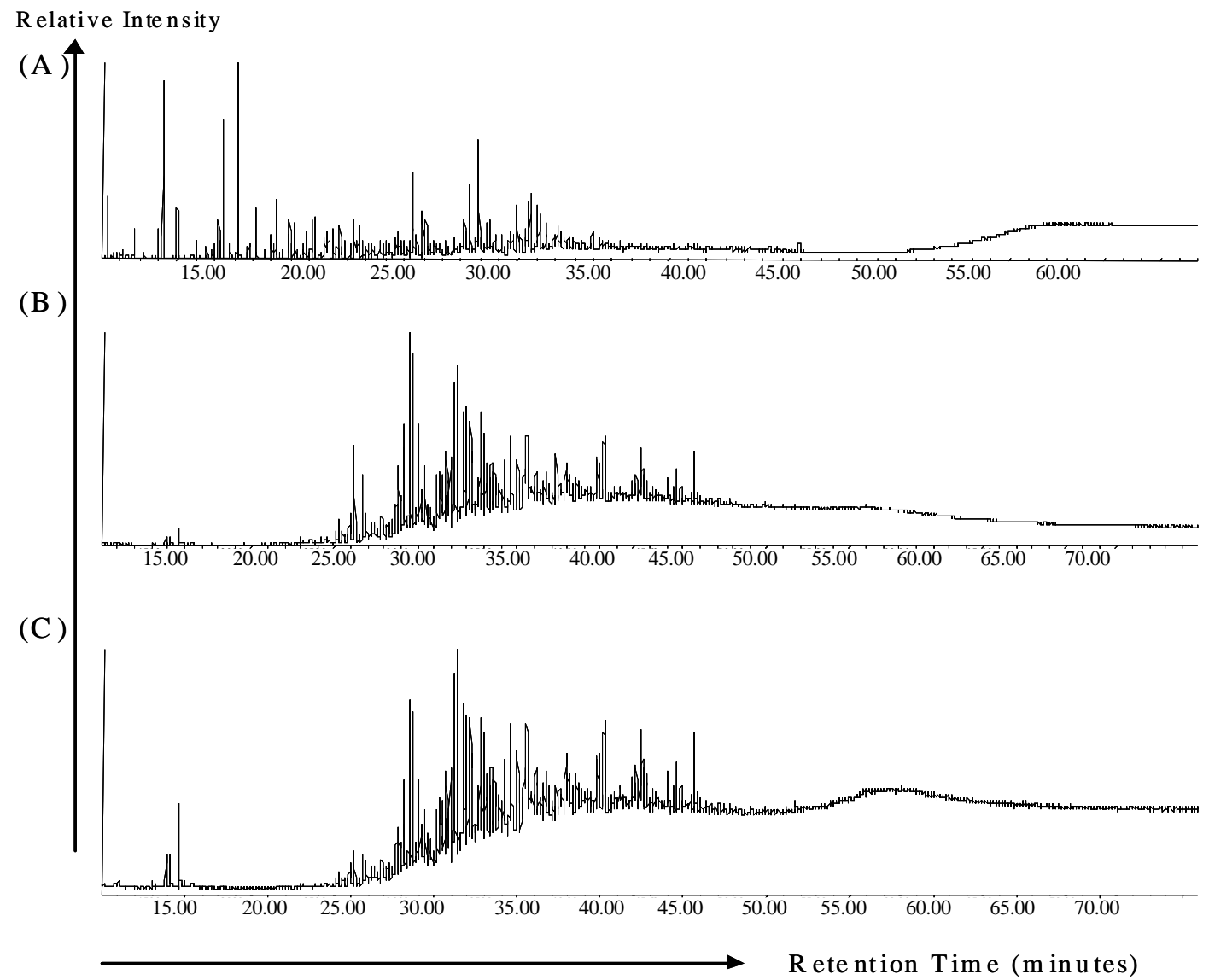

Figure 4. Total ion chromatograms of the aromatic hyodrocarbon fraction from the (A) Original oil, (B) Extracted oil at day 0, and (C) Extracted oil at day 39.

\section{Saturated Biomarkers}

The total ion chromatograms of saturated hydrocarbons isolated from the Barrow crude oil and contaminated soils (day 0 and 39) are shown in Figure 4.

The effects of biodegradation on the diastereomers of pristane and phytane were also determined based on changes in relative abundances ratio. This ratio the diastereomers of pristane and phytane are presented in the Table 3.2. Generally, the ratio decreases consistently for samples at day 0 and day 39 due to the decrease in abundances of pristane.

The abudance of pristane and phytane diasterioisomers is shown in Figure 6. The earlier eluting component (phytane) contains both $R R R$ and $R R S$ configurations as well as the corresponding enantiomers SSS and SSR, the second eluting component contains phytane with $S R S$ and SRR configurations (Table 1.1. n3, n4 and n5). For pristane the second eluting peak is a meso-form $(R S=\mathrm{SR})$, while the second eluting component is pristane with $R R$ and $S S$ configurations.

For the samples there is a slight decrease in stereoisomericratio of pristane and phytane, which represents the decrease in relative abundances of $R R$ and $S S$ of pristane and $R R R$ and $R R S$ in phytane as biodegradation has proceeded.

The effects of biodegradation on the diastereomers of pristane and phytane were also determined based on changes in relative abundances ratio. This ratio the diastereomers of pristane and phytane are presented in the Table 2. Generally, the ratio decreases consistently for samples at day 0 and day 39 due to the decrease in abundances of pristane.

For the samples there is a slight decrease in stereoisomericratio of pristane and phytane, which represents the decrease in relative abundances of $R R$ and $S S$ of pristane and $R R R$ and $R R S$ in phytane as biodegradation has proceeded.

Assessing the rate of biodegradation of the crude oil spilled on soils is a tremendous technique for soil 
Table 2. Relative abundances of acyclic isoprenoids measured in extract oils removed from contaminated soils.

\begin{tabular}{lcccc}
\hline \multirow{2}{*}{ Oil Samples } & \multicolumn{4}{c}{ Acyclic Isoprenoid parameters } \\
& $\operatorname{Pr} / \mathrm{Ph}$ & $\mathrm{PrDR}^{*}$ & $\mathrm{PhDR}^{+}$ & PrDR/PhDR \\
\hline Original Barrow Oil & 1.97 & 1.08 & 1.17 & 2.83 \\
Extracted Oil at day 0 & 1.30 & 0.94 & 0.77 & 1.63 \\
Extracted Oil at day 39 & 1.39 & 1.04 & 0.92 & 1.13 \\
\hline
\end{tabular}

* PrDR (pristane diastereomer ratio) is calculated by dividing the area under the meso-pristane of the doublet by the area under the peak representing the $R R$ and $S S$ enantiomers, using the formula $[R S /(R R+S S)]$. R refers to "rectus" or clockwise configuration. S refers to "sinister" or anticlockwise configuration.

${ }^{+} \mathrm{PhDR}$ (phytane diastereomer ratio) is determined by dividing the area under the first eluting peak of phytane doublet by the area under the second eluting peak.

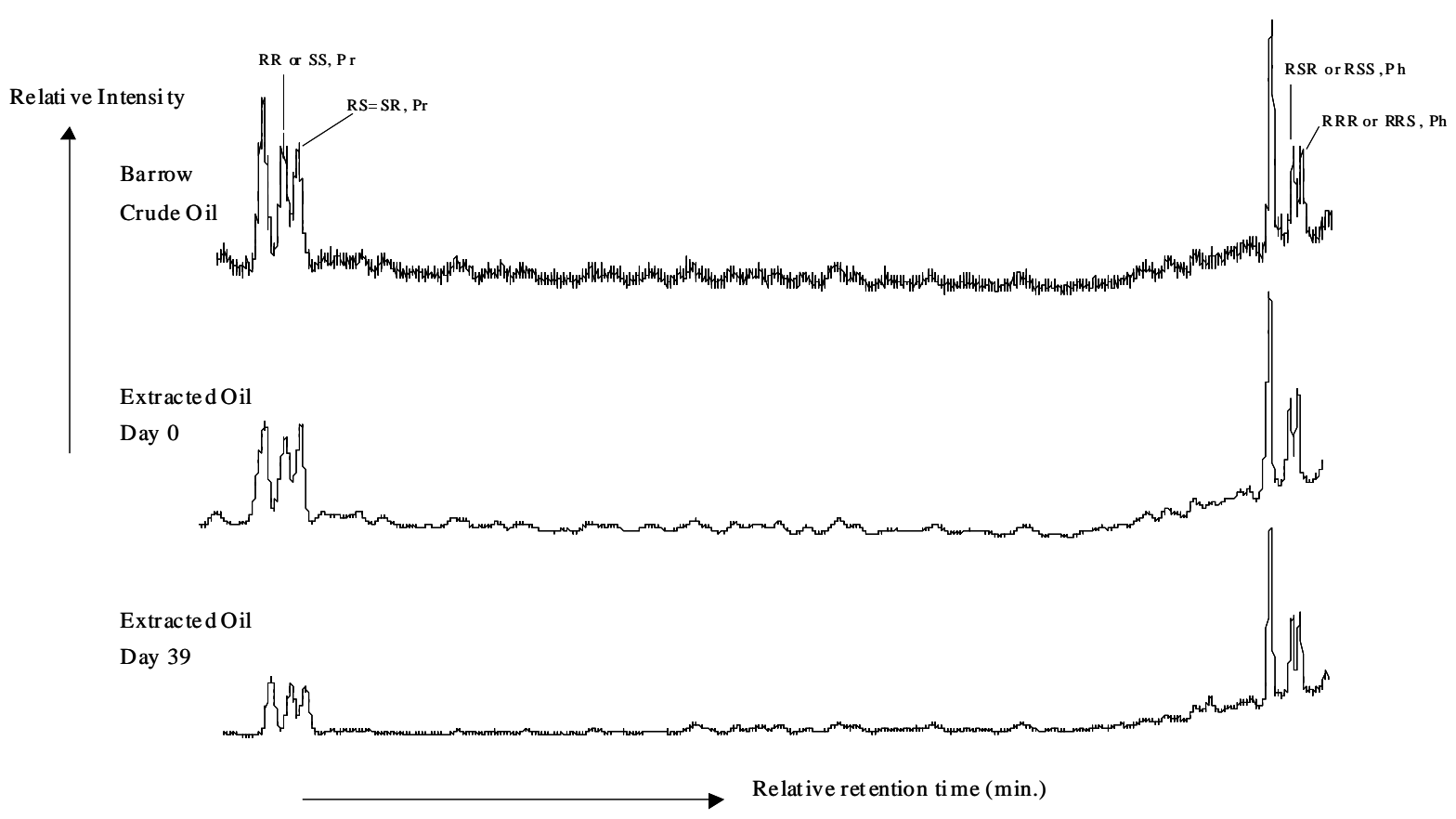

Figure 6. Gas chromatograms of diastereoisomers for pristane, $6(R) 10(R)-(R R)$, or $6(S) 10(S)-(S S)$ for the first eluting peak and $6(R) 10(S)-(R S=)$ for the second eluting peak and phytane, $6(R) 10(S) 14(R)-R S R$ and $6(\mathrm{R}) 10(\mathrm{~S}) 14(\mathrm{~S})$-RSS for the first peak and $6(R) 10(R) 14(R)-R R R$ and $6(R) 10(R) 14(S)-R R S$ for second eluting peak.

recovering. Oil bioremediation as a result of microbial activity was the greatest in the agricultural soil as the soil has experienced regular incorporation of crop residues and fertilizers. It was expected that the greater microbial respiration found in the agricultural soil would be reflected in the size of the microbial population. Therefore, microbes would utilize the crude oil as a source of food. Further investigation 46 on nutrients requirements for soils hopefully will improve the remediation of spill sites which was not covered in this study.

\section{CONCLUSIONS}

The results from this study show that the extent of biodegradation of Barrow crude oil contaminated 
soil could be determined on the basis of changes in the composition of the saturated hydrocarbons and aromatic hydrocarbon distributions over 39 days by GC-MS analyses. These changes were accompanied by the alteration of the polycyclic aromatic hydrocarbons, in particular the alkylnapthalenes. It was evident that the 2-MN was more susceptible to biodegradation than the 1-MN.

The depletion of the $n$-alkanes particularly the lower molecular weight $n-\mathrm{C}_{6}-n-\mathrm{C}_{12}$ were removed at an early stage of biodegradation. As biodegradation proceeded, changes in pristine/phytane ratio occurred. The decrease in the PrDR/PhDR ratio was due to the loss of the RR and SS of pristane as a result of biodegradation.

As a result of the above observations, the biodegradation level of oil from the contaminated soils at day 0 and day 39 was assigned at 2-3.

\section{REFERENCES}

Barron A. 2004. The Limiting Effects of High Oil Concentration and Low Soil Mixture on the Bioremediation of Oil Contaminated Soils. Honours Thesis, School of Natural and Agricultural Sciences, University of Western Australia. Perth.

Bispo A, MJ Jourdain and M Jauzein. 1999. Toxicity and genotoxicity of industrial soils polluted by polycyclic aromatic hydrocarbons (PAHs). Organic Geochem 30 (8, Part 2): 947-952.

Brown G and W Maher. 1992. The occurrence, distribution and sources of polycycic aromatic hydrocarbons in the sediments of the Georges River estuary, Australia. Organic Geochem 18(5): 657-668.

Budzinski H, N Raymond, T Nadalig, M Gilewicz, P Garrigues, JC Bertrand and P Caumette. 1998. Aerobic biodegradation of alkylated aromatic hydrocarbons by a bacterial community. Organic Geochem 28 (5): 337-348.

Chang BV, LC Shiung and SY Yuan. 2002. Anaerobic biodegradation of polycyclic aromatic hydrocarbon in soil. Chemosphere 48 (7): 717-724.

Davie A. 2004. Bioremediation of Oil-Contaminated Soil on Barrow Island, Western Australia. Honours Thesis, School of Natural and Agricultural Sciences. University of Western Australia, Perth.

Fisher SJ, R Alexander, RI Kagi and G.A Oliver. 1998. Aromatic hydrocarbons as indicators of petroleum biodegradation and multiple accumulation events in
North Western Australian Oil Reservoirs. In: PG Purcel and RR Purcel (eds.) The sedimentary Basins of Western Australia 2: Proceedings of the WA Basins Symposium August $30^{\text {th }}$-September $2^{\text {nd }}$, 1998. Perth, WA, pp. 185-194.

Henner P, M Schiavon, V Druelle and E Lichtfouse. 1999. Phytotoxicity of ancient gaswork soils. Effect of polycyclic aromatic hydrocarbons (PAHs) on plant germination. Organic Geochem 30 (8, Part 2): 963969.

Huang H, BFJ Bowler, TBP Oldenburg and SR Larter. 2004. The effect of biodegradation on polycyclic aromatic hydrocarbons in reservoired oils from the Liaohe basin, NE China. Organic Geochem 35 (1112): 1619-1634.

Jiang C. 1998. Polycyclic aromatic hydrocarbons and their geochemical significance. Application to Sediments from the Northern Carnarvon Basin. PhD Thesis. School of applied chemistry. Curtin University of Technology. Perth.

Loehr RC. 1991. Bioremediation of PAH Compounds in Contaminated Soil. In: EJ Calabrese and PT Kostecki (eds), Hydrocarbon Contaminated Soils and Groundwater $2^{\text {nd }}$ Edition. Lewis Publishers, Inc, London, pp. 213-221.

Peters KE and JM Moldowan. 1993. The Biomarker Guide: Interpreting Molecular Fossils in Petroleum and Encient Sediments. Prentice-Hall Inc, New Jersey.

Pospisil M, M Voldrich, M Marek and M Cerovsky. 1996. Bioremediation of soil contaminated with polycyclic aromatic hydrocarbons (PAHs). Inter Biodet Biodeg 37 (3-4): 259.

Sauer TC, J Michel, MO Hayes and DV Aurand. 1998. Hydrocarbon characterization and weathering of oiled intertidal sediments along the Saudi Arabian Coast two years after the Gulf War oil spill. Environ Inter 24 (1-2): 43-60.

Skiba RS, N Gilbertson and JJ Severns. 1992. Biological treatment: soil impacted with crude oil. In: EJ Calabrese and PT Kostecki (eds), Hydrocarbon Contaminated Soils and Groundwater $2^{\text {nd }}$ edition. Lewis Publishers, Inc., London, pp. 409-415.

Volkman JK, R Alexander, RI Kagi, SJ Rowland and PN Sheppard. 1984. Biodegradation of aromatic hydrocarbons in crude oils from the Barrow Sub-basin of Western Australia. Organic Geochem 6: 619-632.

Watkins L. 1996. The remediation of oil and saline contaminated soils on Barrow Island from production and waterflood flowline leaks. Honours Thesis. Agriculture Faculty. University of Western Australia, Perth. 